\title{
Characterization of a natural surfactant from an essential oil from neem (Azadirachta indica A. Juss) for textile industry applications
}

Textile Research Journal $0(0)$ I-8 (C) The Author(s) 2021 Article reuse guidelines: sagepub.com/journals-permissions DOI: $10.1177 / 00405175211007518$ journals.sagepub.com/home/trj @SAGE

\author{
Christiane Siqueira de Azevedo Sá', \\ Rasiah Ladchumananandasivam', Cátia GFT Rossi², \\ Rita K da Silva ${ }^{3}$, Wilka da Silva Camboim ${ }^{3}$, Andrea Zille ${ }^{4}$, \\ Jorge Padrão ${ }^{4}$ and Késia K de Oliveira Souto Silva ${ }^{3}$
}

\begin{abstract}
Surfactants are multipurpose active compounds and are ubiquitously present in detergents. Detergent demand spiked due to the current COVID-19 pandemic, further alerting to the need to replace petrochemical synthetic surfactants with natural and renewable surfactants to mitigate further environmental damage. The neem tree (Azadirachta indica A. Juss) is a fast-growing tree that provides a multitude of commodities, namely neem oil. Neem oil possesses insecticidal and medicinal activity. This work reports the extraction and characterization of a surfactant from neem oil (SNO), displaying a yield of approximately $100 \%$. SNO exhibited suitable detergent characteristics with a high potential to be used as a cleansing agent for textile applications, such as high $\mathrm{pH}$ value $(10 . \mathrm{I})$, suitable foaming of $\mathrm{I} .5 \mathrm{~cm}$ and a $\mathrm{critical}$ micelle concentration of nearly $0.12 \mathrm{~g} \mathrm{~mL}^{-1}$. In addition, SNO showed a moderate bactericidal activity against Escherichia coli and bacteriostatic activity against Staphylococcus aureus, both common nosocomial pathogens. Therefore, SNO has a good potential to be used in medical textile applications due to its detergent and bactericidal properties. Finally, an economical overview of the SNO production process was assessed, underscoring its viability.
\end{abstract}

\section{Keywords}

Surfactant, neem oil, bactericidal, saponification, Azadirachta indica

The staggering concentrations of petrochemical-based plastic waste present in the environment represent over 5 billion metric tons. ${ }^{1}$ This massive plastic waste concentration allied to it highly recalcitrant nature is causing an increasing apprehension to a more informed society that demands the development of novel products able to replace common plastic or petrochemicalbased reactants. These novel active substances must be obtained from renewable resources that represent low to non-environmental impact during their entire life cycle. Moreover, the development of novel environmentally friendly active substances must display an enhanced efficacy to be able to compete with low-cost petrochemical-based substances. Surfactants are unquestionably an active substance with an intensive and widespread use. Surfactants may be synthetic or natural amphiphilic compounds, displaying the same molecule hydrophilic polar groups and hydrophobic non-polar groups. ${ }^{2}$ The non-polar group, also named as tail, is composed of one or two alkyl chains comprising between 8 and 22 carbons. ${ }^{3}$ In particular, surfactants' hydrophobic tail may contain fluorine.

\footnotetext{
'Department of Mechanical Engineering, Federal University of Rio Grande do Norte, Natal, Brazil

${ }^{2}$ Faculdade Natalense de Ensino e Cultura, Natal, Brasil

${ }^{3}$ Department of Textile Engineering, Federal University of Rio Grande do Norte, Natal, Brazil

${ }^{4}$ Centre for Textile Science and Technology, University of Minho, Guimarães, Portugal

Corresponding author:

Andrea Zille, 2C2T - Centro de Ciência e Tecnologia Têxtil, Universidade do Minho, Campus de Azurém 4800-058 Guimarães, Portugal.

Email: azille@2c2t.uminho.pt
} 
These extremely hydrophobic fluorocarbon tails promote the development of bulkier clusters, due to fluorine's larger atomic size and stronger hydrophobicity. ${ }^{4}$ Surfactants' polar section, or head, encompasses ionic groups (anions or cations), and may have an amphoteric behavior, meaning that it may display an acid or alkaline property depending on the $\mathrm{pH}$ of the solution. The surfactant hydrophilic region promptly links to water through hydrogen bonding, whereas the hydrophobic tail stabilizes with lipids through van der Waals interactions. ${ }^{5}$ Due to these properties, surfactants are able to alter both surface tension and interfacial tension between liquids, gases and solid-liquid surfaces (wetting systems). ${ }^{6}$ This behavior makes surfactants excellent compounds to act as dispersion agents, detergents, emulsifiers, oil recovery agents and foamforming agents, among others. ${ }^{7,8}$

The use of synthetic surfactants has been increasing considerably since the beginning of the 20th century, and presently is among the most produced synthetic chemicals worldwide. The estimated surfactant production is more than 12 thousand metric tons and has an estimated annual increase between 3 and 4\%. Domestic and industrial applications result in significant amounts of waste discharge in soil, fresh water and marine water environments. Due to the increasing demand of the detergent and cosmetic industry, the surfactant annual production will have a significant increase, particularly because of the present detergent demand due to the COVID-19 pandemic. These synthetic surfactants are usually non-biodegradable and produce a negative impact, not only in the environment, but also to human health, because surfactants are responsible for the development of dermatitis, respiratory problems and irritations, among other complications. Therefore, recently, carbohydrates, amino acids and organic acids obtained from renewable sources are being increasingly used as raw materials for the production of surfactants. ${ }^{8-10}$ Surfactants of vegetable origin, also known as biosurfactants, are renewable compounds that can be synthesized from a wide scope of renewable substrates and display an impressive chemical diversity. This allows the development of tailored applications for specific areas from different fields, such as petrochemical industry, food industry, cosmetics and pharmaceutical companies. Some notable advantages of biosurfactants in comparison with synthetic compounds include biodegradability, biocompatibility, low cost, similar efficiency using lower surfactant concentration, higher stability toward $\mathrm{pH}$, temperature and ionic strength variations and higher foaming capability. These compounds can be produced through the biotransformation of petrol hydrocarbons or from renewable substrates, such as waste from vegetable processing, glycerol and oils, among others. ${ }^{11}$
In the biological systems the surfactants are to solve solubility problems and to work as emulsifiers, dispersants and surface tension modifiers, thus essentially playing the same role as the synthetic surfactants. There are a few reports in the literature describing the synthesis of surfactants from renewable sources. These materials are the saponins, which are active surfactants obtained from the pericarp of chestnuts, soy and chickpeas. These vegetable surfactants are traditionally used in India for textile washing, as shower gel and as a popular medicine due to their capability to produce foam in water. ${ }^{12}$

Vegetable oils and essential oils, similarly to surfactants, also possess a non-polar group that is widely used in different industrial areas. Vegetable oils are a complex blend of volatile compounds and lipophilic compounds. ${ }^{13,14}$ The oils may be classified as fixed and essential. The fixed vegetable oils are composed of a complex mixture of lipid compounds and are commonly obtained from seeds. Fixed oils are characterized by poor water solubility and non-volatility and are usually susceptible to light and heat, whereas essential oils are low-molecular-weight, lipophilic and volatile compounds, mainly present in aromatic plants. ${ }^{15,16}$ Both fixed and essential oils have been widely used, and their application has been constantly increasing due to the current demand for natural products. Therefore, large quantities of oils are produced worldwide for the manufacture of fragrances and cosmetics and to supply health industries and the textile industry. ${ }^{17}$ Neem oil is collected from Azadirachta indica (A. Juss), of the family Meliaceae. Despite its Asian origin, this plant can be easily found in different regions; due to its resilience it is able to withstand adverse soil and climate conditions. Moreover, $A$. indica has a rapid growth of approximately $0.6 \mathrm{~m} \mathrm{year}^{-1}$ in height. ${ }^{18}$ Neem oil is extracted from fruits and seed and widely used as an insecticide due to the presence of azadirachtin in its formulation. ${ }^{19,20}$ Neem oil obtained from the seeds of $A$. indica is described to contain at least 100 biologically active compounds. ${ }^{21} A$. indica seeds comprise $45 \%$ of a brownish oil, mainly composed of oleic acid $(50-60 \%)$, palmitic acid $(15-19 \%)$, stearic acid (14-19\%) and linoleic acid (8-16\%), and it contains a spicy flavor and an unpleasant and persistent odor. ${ }^{22}$ Several references describe the use of neem oil as soaps through the saponification; in particular, one study describes the production and characterization of soaps obtained from different oils, including neem oil. ${ }^{23}$ The produced neem oil soap was characterized as a hard soap with a $\mathrm{pH}$ of 9.75. Other researchers also produced soap bars from the saponification of neem oil and attained a yellowish soap with a $\mathrm{pH}$ of 10.4. ${ }^{23}$ Therefore, this work envisaged the production and characterization of a surfactant from neem oil 


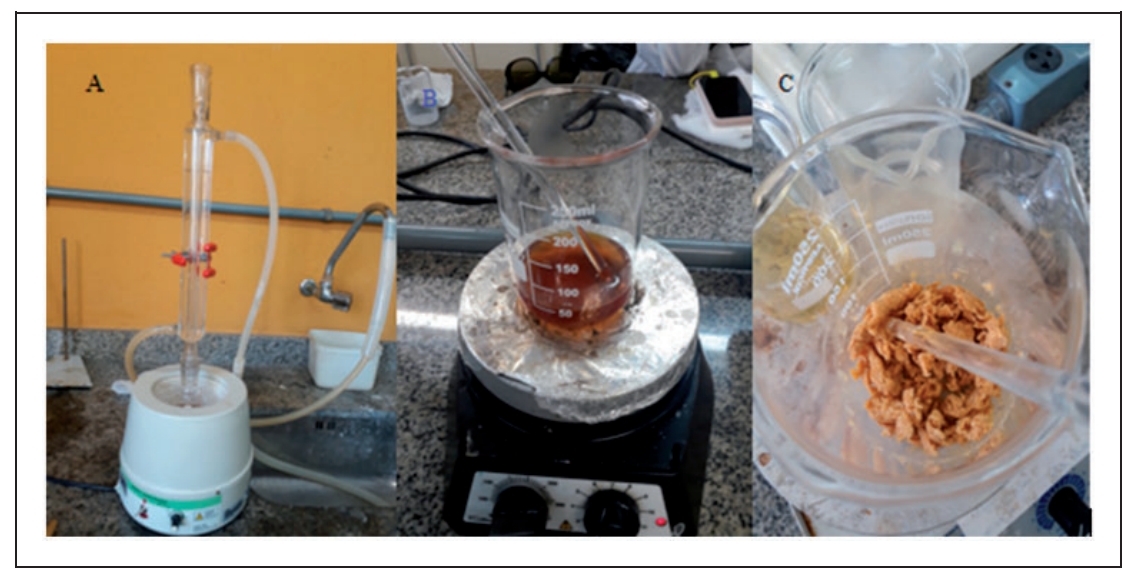

Figure I. Surfactant from neem oil (SNO) extraction process: (a) reflux procedure, (b) ethanol evaporation step and (c) SNO agglomerates.

(SNO), which is a natural, environmentally friendly surfactant. The results collected depict the high applicability of the obtained surfactant in several contexts, such as domestic use and textile industry. Moreover, it can be used for sanitizing several hospital textiles, such as bed sheets and privacy curtains, among other applications.

\section{Experimental methods}

\section{Characterization of neem oil}

Neem oil was commercially purchased, and its physicochemical properties were characterized in terms of acid value, saponification value, peroxide value, refractive index, density and molecular weight. To determine the acid value, the procedure was used as described previously. ${ }^{24}$ Briefly, $1.5 \mathrm{~g}$ of neem oil was solubilized in $20 \mathrm{~mL}$ of an ether ethanol solution $(25 \% \mathrm{v} / \mathrm{v})$ and an aliquot of phenolphthalein was used as a $\mathrm{pH}$ indicator. Sodium hydroxide (1 M) was used for the titration. The saponification value was estimated using $2 \mathrm{~g}$ of neem oil and a $20 \mathrm{~mL}$ sodium hydroxide solution $(5 \% \mathrm{w} / \mathrm{v})$ in distilled water and was heated for $30 \mathrm{~min}$ at $50^{\circ} \mathrm{C}$. After the sample reached room temperature, an aliquot of phenolphthalein was added, and the solution was titrated with hydrochloric acid $(0.5 \mathrm{M})$. The peroxide value was determined using $5.0 \mathrm{~g}$ of neem oil and $86.2 \mathrm{~g}$ of potassium iodide. The released iodide was estimated using sodium thiosulfate. Starch was used as standard. The refractive index was obtained using refractometer Abbe, CILAB. Neem oil density was obtained using a pycnometer.

\section{SNO extraction}

SNO was collected through saponification by mixing $10 \mathrm{~g}$ of neem oil with $10 \mathrm{~mL}$ of a sodium hydroxide solution $(30 \% \mathrm{w} / \mathrm{v})$. During the saponification process a reflux condenser was used to prevent the solvent loss and a heating mantle was used to maintain the reaction at $100^{\circ} \mathrm{C}$ for $2 \mathrm{~h}$. Afterwards the $\mathrm{SNO}$ sample was placed on top of a heating plate at $70^{\circ} \mathrm{C}$ for approximately $8 \mathrm{~h}$ to evaporate completely the ethanol and was then exposed to sunlight for drying (Figure 1).

\section{SNO characterization}

SNO was submitted to several characterization methods, which encompassed the following: $\mathrm{pH}$ value, surface tension, foaming test, scanning electron microscopy (SEM) coupled to energy dispersive X-ray spectroscopy (EDS) and Fourier transform infrared spectroscopy (FTIR). The $\mathrm{pH}$ value was determined as described elsewhere, ${ }^{25}$ using a $1 \% \mathrm{w} / \mathrm{v}$ SNO aqueous solution and a pH meter (NI PM, NOVA Instruments). Surface tension was calculated using nitrogen at a constant pressure of $200 \mathrm{kPa}$ at $30^{\circ} \mathrm{C}$ in a Sensadyne tensiometer. The foaming test was performed exposing a $4 \% \mathrm{w} / \mathrm{v}$ SNO aqueous solution to vigorous agitation with a magnetic stirrer for $2 \mathrm{~min}$ in a $100-\mathrm{mL}$ beaker. Afterwards, the solution was left to rest for $10 \mathrm{~min}$ and the foam height was measured. Uncoated SNO sample SEM images and EDS analysis were obtained through backscattering electrons using a scanning electron microscope (TM3000, Hitachi) with an accelerating voltage of $15 \mathrm{kV}$. In addition, SNO samples were also coated through sputtering (polaron). FTIR spectra of the surfactant were collected using a Shimadzu spectrometer, model FTIR-8400S, IRAffinity-1 (Shimadzu, Kyoto, Japan), coupled with an attenuated total reflectance accessory, the PIKE MIRacle ${ }^{\mathrm{TM}}$ single reflection with a ZnSe crystal (PIKE Technologies, Madison, WI, USA). Spectra were obtained in the range of 4000$500 \mathrm{~cm}^{-1}$, from 30 scans at a resolution of $4 \mathrm{~cm}^{-1}$. All measurements were performed in triplicate. 


\section{Bactericidal analysis}

The bactericidal properties of SNO were evaluated through the disk diffusion susceptibility test as described in the literature. ${ }^{26,27}$ The bacteria tested were from the American Type Culture Collection (ATCC): Grampositive Staphylococcus aureus ATCC 25923 and Gram-negative Escherichia coli ATCC 25922. Vancomycin $\left(30 \mu \mathrm{g} \mathrm{mL}^{-1}\right)$ was used as positive control for S. aureus, and gentamycin $\left(10 \mu \mathrm{g} \mathrm{mL}^{-1}\right)$ for E. coli. SNO $(10 \% \mathrm{w} / \mathrm{v})$ and the antibiotics were tested using a cellulose disk of $6 \mathrm{~mm}$. Each bacterium was incubated in tryptic soy broth for $12 \mathrm{~h}$ at $37^{\circ} \mathrm{C}$ at a shaking speed of $120 \mathrm{rpm}$. From these pre-inocula, each of the bacterium concentrations was adjusted to approximately $1.0 \times 10^{7} \mathrm{CFU} \mathrm{mL} \mathrm{m}^{-1}$ and inoculated in tryptic soy agar at a mild temperature and plated in 90-mm Petri dishes. Once the tryptic soy agar was solidified, the discs were carefully placed on the inoculated medium under aseptic conditions. The plates were incubated for at least $18 \mathrm{~h}$ at $37^{\circ} \mathrm{C}$ and the zone of inhibition ( $\left.\mathrm{ZoI}\right)$ was determined.

\section{Economical overview}

An industrial scale economical overview was performed based on the production process described by this work (Supplemental material). In a short description, the industrial process would comprise four critical pieces of equipment: a saponification reactor, a hot plate for ethanol evaporation, an industrial blender for SNO liquid preparation and an automatic bottle filling equipment for the preparation of the final product. Several equipment units were considered to ensure redundancy. The economical overview reference value was based on the purchase equipment cost (PCE). The direct facilities' costs were used to estimate the fixed capital $\left(\mathrm{I}_{\mathrm{F}}\right)$, encompassing construction costs $(50 \%$ of PCE), electrical installation (15\% of PCE), piping (20\% of PCE), control and instrumentation $(15 \%$ of PCE), health and security costs (1.5\% of PCE) and design and engineering costs $(20 \%$ of PCE). The total investment (TI) was calculated according to equation (1)

$$
\mathrm{TI}=\mathrm{I}_{\mathrm{F}}+\mathrm{I}_{\mathrm{C}}
$$

where $\mathrm{I}_{\mathrm{C}}$ corresponds to the contingency investment.

The calculation of the total cost (TC) was performed using equation (2)

$$
\mathrm{TC}=\mathrm{CPF}+\mathrm{CPL}+\mathrm{LC}
$$

where CPF is the cost proportional to fixed capital, CPL is the cost proportional to production load and $\mathrm{LC}$ is the labor cost.
The net benefit $\left(\mathrm{R}^{\prime}\right)$ was estimated using equation (3)

$$
\begin{aligned}
\mathrm{R}^{\prime}= & (\text { turnover }-\mathrm{TC}) \\
& -\left[\left((\text { turnover }-\mathrm{TC})-\mathrm{CD} \times \mathrm{I}_{\mathrm{F}}\right) \times \mathrm{TR}\right]
\end{aligned}
$$

where $\mathrm{CD}$ and TR are capital depreciation and tax rate, respectively.

The net present value (NPV) was determined using equation (4)

$$
\mathrm{NPV}=-\mathrm{I}_{\mathrm{F}}+\frac{\mathrm{R}^{\prime}}{(1+\mathrm{i})^{\mathrm{y}}}
$$

where $\mathrm{i}$ is the discount rate and y the time (in the current overview, 10 years were used).

The return on investment (ROI) was estimated using equation (5)

$$
\mathrm{ROI}=\frac{\mathrm{TI}-\mathrm{R}^{\prime}}{\mathrm{TI}} \times 100
$$

\section{Results and discussion}

The neem oil physicochemical characteristics are represented in Table 1 . The density of the neem oil was similar to the values reported in the literature $(0.92$ and $\left.0.88 \mathrm{~g} \mathrm{~mL}^{-1}\right){ }^{28,29}$ The saponification value was nearly 1.5 -fold higher than the exhibited neem oil collected from the seed, and close to the reported standard values. ${ }^{30,31}$ The refractive index value was also in agreement with the standard values for the neem oil. ${ }^{31}$

The estimated molecular weight of the neem oil was $773.02 \mathrm{~g} \mathrm{~mol}^{-1}$. This value was estimated based on the saponification value, which provides an indirect weight value of the fatty acids obtained after the saponification process, because these values are negatively correlated.

The obtained SNO presented a yellowish color similar to the neem oil; however, unlike the neem oil it displayed a soft and pleasant smell (Figure 2). As observed in Figure 2(b), the SNO forms a clear

Table I. Neem oil chemical characterization

\begin{tabular}{lr}
\hline Properties & Values \\
\hline Acidity value $(\%)$ & 1.28 \\
Saponification value $\left(\mathrm{mgKOH} \mathrm{g}^{-1}\right)$ & 217.33 \\
Peroxide value $\left(\mathrm{mEqO} \mathrm{kg}^{-1}\right)$ & 1.70 \\
Refractive index & 1.48 \\
Density $\left(\mathrm{g} \mathrm{mL}^{-1}\right)$ & 0.96 \\
Molecular weight $\left(\mathrm{g} \mathrm{mol}^{-1}\right)$ & 773.02 \\
\hline
\end{tabular}


dispersion in water, thus its hydrophilic-lipophilic balance is clearly higher than 10 .

The $\mathrm{pH}$ of the SNO aqueous solution was 10.1, which is within the $\mathrm{pH}$ range for soap of $8-10.5$. Such a high $\mathrm{pH}$ is due to the incomplete alkaline hydrolysis during the saponification process. Despite the high $\mathrm{pH}$ value, the SNO is not corrosive to the skin, in fact, its alkalinity favors its detergent effect. ${ }^{23}$ Surfactants are characterized by their impact on the surface tension, therefore the characterization of SNO effect on the surface tension of a liquid is of paramount importance. The surface tension of a liquid is determined by the molecule's energy at the interface. The energy requirements for displacement of these molecules in adsorption are directly correlated with the surfactant efficacy. The critical micellar concentration was calculated through the estimation of the interception of the two equations of the surface tension (Figure 3). The determined concentration of neem oil surfactant was
$0.1165 \mathrm{~g} \mathrm{~mL}^{-1}$. Therefore, at concentrations above $0.1165 \mathrm{~g} \mathrm{~mL}^{-1}$, the neem oil surfactant will be arranged in micellar structures, whereas in lower concentrations it will be organized in its monomeric form.

For the foaming test, it is important that the surfactant displays a relevant reduction of the surface tension, because the lower the surface tension, the greater amount of foam can be produced with the same amount of agitation..$^{8,15,32,33}$ Moreover, the foaming test is an important indicator of the detergent capability of the surfactant. However, some surfactants have a high detergency efficacy and produce negligible amounts of foam. Foam stability is defined by the surfactant capability preventing the water to quickly run through the foam bubbles. ${ }^{32}$ The foam produced by the extracted surfactant was $1.5 \mathrm{~cm}$, a value within the range of reported values in the literature (Figure 4). ${ }^{30}$

Extracted surfactant SEM images are displayed in Figure 5. The SEM images denote the presence of white

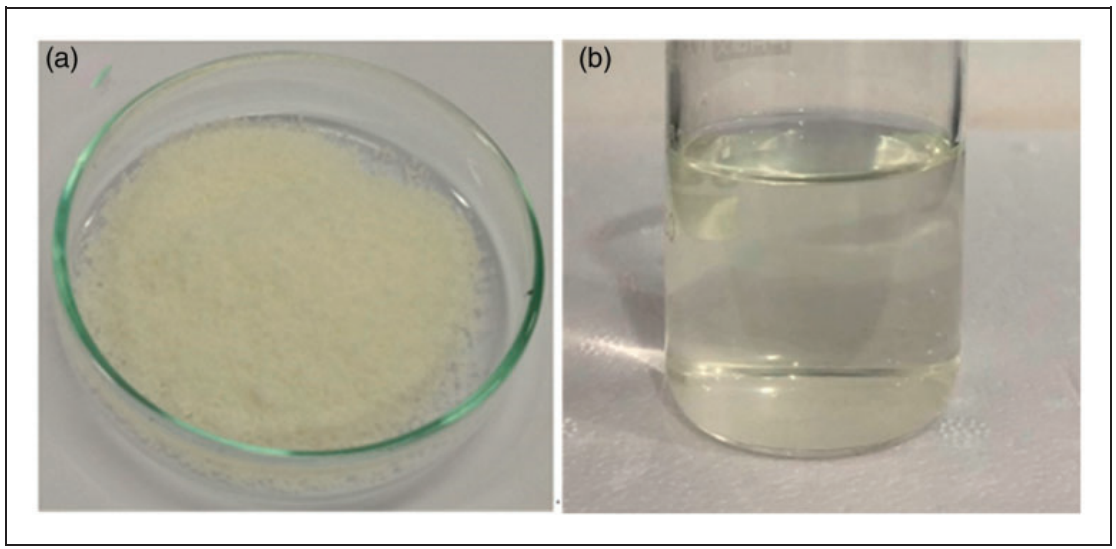

Figure 2. Surfactant from neem oil: (a) in solid state and (b) diluted in distilled water $(2 \% \mathrm{w} / \mathrm{v})$.

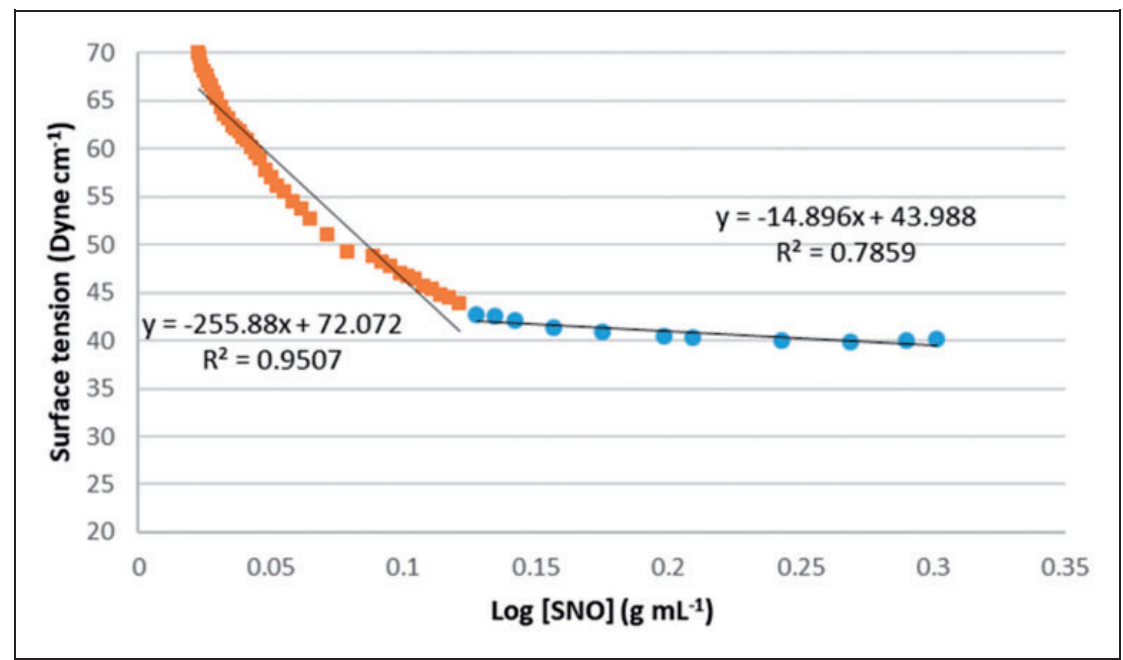

Figure 3. Surfactant from neem oil (SNO) surface tension. 


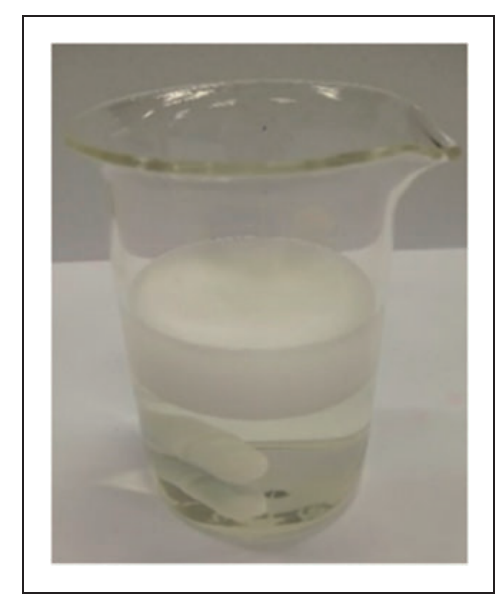

Figure 4. Surfactant foaming test.

crystals on top of the samples (Figure 5(a)). EDS analysis identified these crystals as sodium crystals (Figure 5(b) and (c)). The presence of these crystals most likely originated from the use of sodium hydroxide during the saponification process.

FTIR analysis (Figure 6) depicts the presence of $\mathrm{O}-\mathrm{H}$ stretching (broad band present between 3726 and $3032 \mathrm{~cm}^{-1}$ ) and $\mathrm{O}-\mathrm{H}$ bending $\left(1423 \mathrm{~cm}^{-1}\right)$ solely on SNO, most likely due to the reaction with sodium hydroxide during saponification. The aliphatic stretching of alkane and alkene groups is depicted in the bands that range between approximately 3010 and $2850 \mathrm{~cm}^{-1}$, with a reduced intensity in SNO. Ester bonds $\left(1745 \mathrm{~cm}^{-1}\right)$ are clearly present in neem oil; however, they are not observable in the SNO spectra. SNO exhibits strong bands at $1560 \mathrm{~cm}^{-1}$ and $1445 \mathrm{~cm}^{-1}$, which can be attributed to asymmetric and symmetric carboxylate stretching. ${ }^{34}$ Also, the characteristic stretching of the C-O group is observed at $1050 \mathrm{~cm}^{-1}$. Some of these bands were also observed by other authors. ${ }^{35,36}$ Therefore, the FTIR analysis provides insight on the amphiphilic nature of the SNO molecules. The hydrophilic groups encompass hydroxyl, carbonyl and carboxylate, which are hydrophilic polar and are present on the molecule head, whereas the hydrophobic groups present in the tail comprise hydrophobic groups such as alkanes and alkenes. ${ }^{37}$

The disk diffusion method was used to analyze the antimicrobial activity and the ZoI was assessed. The tested bacteria were $S$. aureus and $E$. coli, with $S$. aureus being considered a model Gram-positive bacterium and $E$. coli a model Gram-negative bacterium. Moreover, both bacteria are responsible for nosocomial infections. The positive controls displayed the expected value for both bacteria (between 22 and 30 $\mathrm{mm})$. For S. aureus the ZoI was present but blurred, which is commonly associated with a bacteriostatic activity. Nevertheless, the ZoI for $S$. aureus was

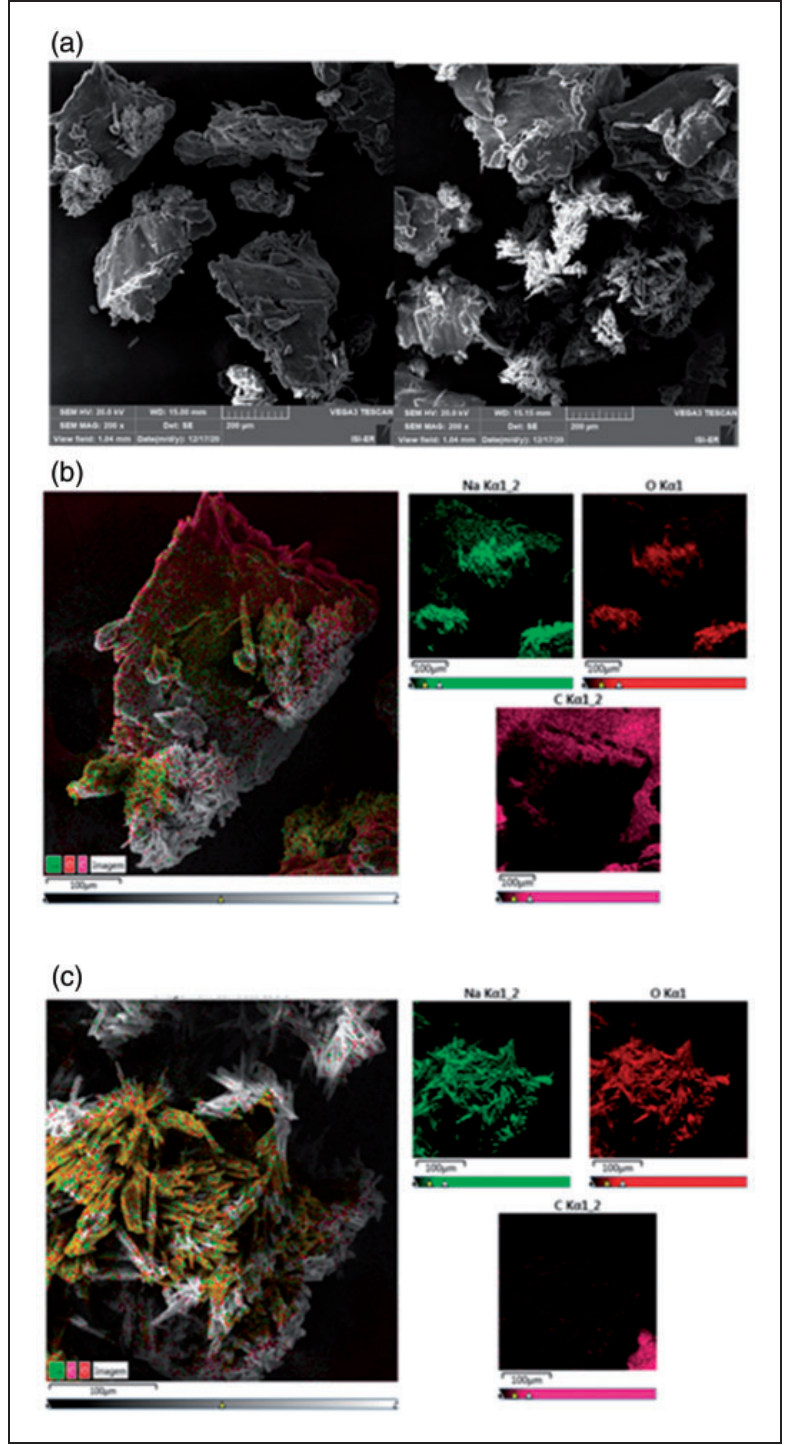

Figure 5. Surfactant from neem oil scanning electron microscopy (SEM) images and energy dispersive $X$-ray spectroscopy (EDS) analysis; the EDS analysis of the images on the right side highlight the presence of sodium $(\mathrm{Na})$, oxygen $(\mathrm{O})$ and carbon (C) elements: (a) SEM images (left uncoated, right coated), (b) SEM and EDS analysis, (c) SEM and EDS analysis focused on the crystals present in the sample.

$14.4 \pm 1.5 \mathrm{~mm}$. On the other hand, E. coli ZoI depicted a clear but weak-to-moderate bactericidal activity $12.0 \pm 1.7 \mathrm{~mm} .^{26}$ Therefore, SNO bactericidal activity against a Gram-negative bacterium may indicate a destabilization of the outer membrane through its surfactant activity. In the literature an antiseptic soap was developed using a mixture of neem oil and shea butter; nevertheless, the soap with $100 \%$ neem oil exhibited a ZoI of $20 \mathrm{~mm}$ against $S$. aureus. ${ }^{38}$ The economical overview of the production of the SNO was assessed through a simulation to determine the feasibility of its industrial process. The performed economical overview 


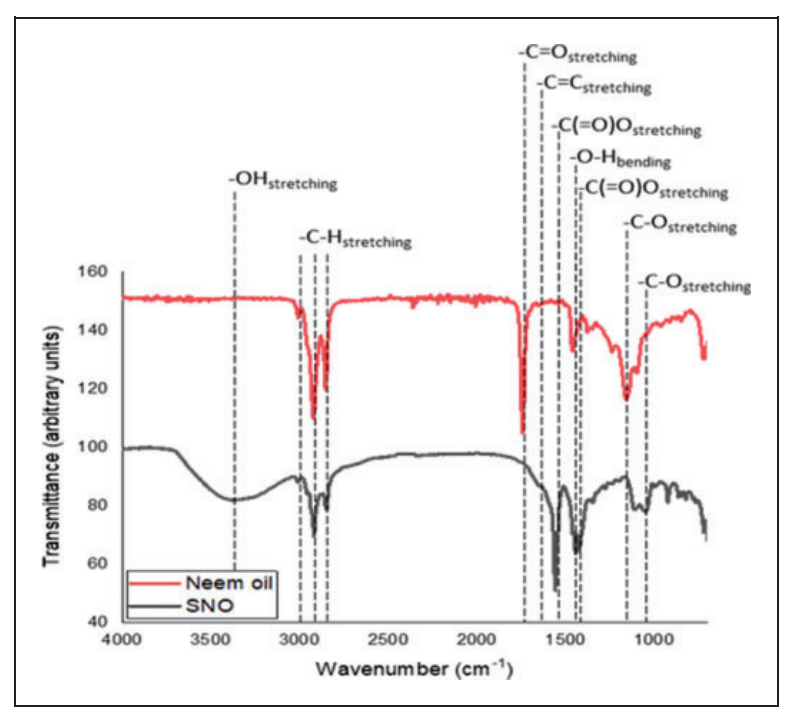

Figure 6. Fourier transform infrared spectroscopy spectra of neem oil and surfactant from neem oil (SNO).

denotes the relatively modest total investment (roughly seven hundred thousand euros) due to the simplicity of the process, which requires common and low-end technology. However, the production costs represent nearly double the investment value, mainly due to the neem oil cost. Nevertheless, this value is easily recovered, even applying a modest profit value. Therefore, the net present value obtained was positive, which highlights the profitability of the process, and the return on investment value may be considered to be high $(71 \%)$. Due to the increasing demand of ecological responsible surfactants, the production of SNO may be considered as very attractive in terms of economic viability and easy to establish.

\section{Conclusions}

SNO was a surfactant obtained with a yield of approximately $100 \%$, through the saponification of neem oil using mild and cost-effective conditions. SNO physicochemical properties were characterized, in particular to observe its potential to be used as a fully natural detergent for hospital textiles, such as patient linens, privacy curtains and medical staff uniforms. SNO exhibited a critical micelle concentration of $0.12 \mathrm{~g} \mathrm{~mL}^{-1}$, a high $\mathrm{pH}$ value (10.1) and an adequate foaming of $1.5 \mathrm{~cm}$. Moreover, unlike the neem oil, SNO has a soft and agreeable odor. Finally, SNO exhibited a weakto-moderate bactericidal activity against a Gramnegative bacterium and a moderate bacteriostatic effect against a Gram-positive bacterium. Its activity may be potentiated with the application of a high washing temperature during hospital textile laundry procedures. Nevertheless, further analysis must be performed to confirm its cleansing and bactericidal efficacy mimicking hospital textile hygiene methodologies. The economic viability and attractiveness are denoted in the economical overview performed, highlighting the need to promote the establishment of sustainable businesses.

\section{Author contributions}

All authors contributed to the writing of the manuscript. All authors have approved the final version of the manuscript.

\section{Acknowledgements}

The authors acknowledge the Federal University of Rio Grande do Norte for carrying out the analyzes through its transversal laboratories

\section{Declaration of conflicting interests}

The authors declared no potential conflicts of interest with respect to the research, authorship, and/or publication of this article.

\section{Funding}

The authors disclosed receipt of the following financial support for the research, authorship, and/or publication of this article: This work was supported by the Brazilian Coordenação de Aperfeịoamento de Pessoal de Nível Superior and by the Portuguese Fundação para Ciência e a Tecnologia, Fundo Europeu de Desenvolvimento Regional and Programa Operacional Competitividade e Internacionalização in the frame of the Portugal 2020 program for the project PLASMAMED PTDC/CTM-TEX/28295/2017.

\section{ORCID iD}

Andrea Zille (D) https://orcid.org/0000-0001-5299-4164

\section{References}

1. Geyer R, Jambeck JR and Law KL. Production, use, and fate of all plastics ever made. Sci Adv 2017; 3: e1700782.

2. Barel AO, Paye M and Maibach HI. Handbook of cosmetic science and technology. CRC press, 2014.

3. Sakamoto K, Lochhead R, Maibach H, et al. Cosmetic science and technology: theoretical principles and applications. Elsevier, 2017.

4. Kovalchuk NM, Trybala A, Starov V, et al. Fluoro- vs hydrocarbon surfactants: why do they differ in wetting performance? Adv Colloid Interface Sci 2014; 210: 65-71.

5. McNamee CE and Kawakami H. Effect of the surfactant charge and concentration on the change in the forces between two charged surfaces in surfactant solutions by a liquid flow. Langmuir 2020; 36: 1887-1897.

6. Banat IM, Makkar RS and Cameotra SS. Potential commercial applications of microbial surfactants. Appl Microbiol Biotechnol 2000; 53: 495-508.

7. De S, Malik S, Ghosh A, et al. A review on natural surfactants. RSC Adv 2015; 5: 65757-65767. 
8. Pradhan A and Bhattacharyya A. Quest for an ecofriendly alternative surfactant: surface and foam characteristics of natural surfactants. J Clean Prod 2017; 150: 127-134.

9. Ivanković T and Hrenović J. Surfactants in the environment. Arch Ind Hyg Toxicol 2010; 61: 95-110.

10. Foley P, Kermanshahi pour A, Beach ES, et al. Derivation and synthesis of renewable surfactants. Chem Soc Rev 2012; 41: 1499-1518.

11. Muntaha S-T and Khan MN. Natural surfactant extracted from Sapindus mukurossi as an eco-friendly alternate to synthetic surfactant - a dye surfactant interaction study. J Clean Prod 2015; 93: 145-150.

12. Schmitt C, Grassl B, Lespes G, et al. Saponins: a renewable and biodegradable surfactant from its microwaveassisted extraction to the synthesis of monodisperse lattices. Biomacromolecules 2014; 15: 856-862.

13. Carvalho IT, Estevinho BN and Santos L. Application of microencapsulated essential oils in cosmetic and personal healthcare products - a review. Int J Cosmet Sci 2016; 38 : 109-119.

14. Amorati R, Foti MC and Valgimigli L. Antioxidant activity of essential oils. J Agric Food Chem 2013; 61: 10835-10847.

15. Tmáková L, Sekretár S and Schmidt Š. Plant-derived surfactants as an alternative to synthetic surfactants: surface and antioxidant activities. Chem Pap 2016; 70: 188-196.

16. Campos EVR, de Oliveira JL, Pascoli M, et al. Neem oil and crop protection: from now to the future. Front Plant Sci 2016; 7: 1494.

17. Do TKT, Hadji-Minaglou F, Antoniotti S, et al. Authenticity of essential oils. Trends Analyt Chem 2015; 66: 146-157.

18. Bisaria A, Tyagi SR and Ahanger MA. Growth performance of different provinces of Azadirachta indica. Indian For 2014; 140: 841-846.

19. Anjali CH, Sharma Y, Mukherjee A, et al. Neem oil (Azadirachta indica) nanoemulsion - a potent larvicidal agent against Culex quinquefasciatus. Pest Manag Sci 2012; 68: 158-163.

20. Saleh Al-Hashemi ZS and Hossain MA. Biological activities of different neem leaf crude extracts used locally in Ayurvedic medicine. Pac Sci Rev A: Nat Sci Eng 2016; 18: 128-131.

21. Benelli G, Bedini S, Cosci F, et al. Larvicidal and ovideterrent properties of neem oil and fractions against the filariasis vector Aedes albopictus (Diptera: Culicidae): a bioactivity survey across production sites. Parasitol Res 2014; 114: 227-236.

22. Nicoletti M, Maccioni O, Coccioletti T, et al. Neem tree (Azadirachta indica A. Juss) as source of bioinsectides. In: Perveen F (ed.) Insecticides: advances in integrated pest management. Rijeka, Croatia: InTech, 2012, pp.411-428.
23. Mak-Mensah E and Firempong C. Chemical characteristics of toilet soap prepared from neem (Azadirachta indica A. Juss) seed oil. Asian J Plant Sci Res 2011; 1: 1-7.

24. Nielsen SS. Introduction to food analysis. In: Food analysis. Springer, 2017, pp.3-16.

25. Atolani O, Olabiyi ET, Issa AA, et al. Green synthesis and characterisation of natural antiseptic soaps from the oils of underutilised tropical seed. Sustain Chem Pharm 2016; 4: 32-39.

26. Tavares TD, Antunes JC, Padrão J, et al. Activity of specialized biomolecules against Gram-positive and Gram-negative bacteria. Antibiotics 2020; 9: 314.

27. Padrão J, Ribeiro S, Lanceros-Méndez S, et al. Effect of bacterial nanocellulose binding on the bactericidal activity of bovine lactoferrin. Heliyon 2020; 6: e04372.

28. Machado G, Calil C Jr, Polito W, et al. Preservante natural de madeira para uso na construção civil: óleo de neem. Minerva 2006; 3: 1-8.

29. Paes JB, de Souza AD, de Lima CR, et al. Rendimento e características físicas dos óleos de nim (Azadirachta indica) e mamona (Ricinus communis). Floresta $e$ Ambient 2015; 22: 134-139.

30. Warra A, Wawata I and Yauri AB. Soap preparation from mechanically cold pressed Nigerian neem (Azadiracta indica) seed oil. Chemsearch J 2011; 2: 12-15.

31. Usman J, Okonkwo P and Shehu M. Investigation into the usage of solvent for extracting neem oil from neem seed for industrial application. Acad J Interdiscip Stud 2014; 3: 39.

32. Daltin D. Tensoativos: química, propriedades e aplicações. Editora Blucher, 2011.

33. Jian H-1, Liao X-x, Zhu L-w, et al. Synergism and foaming properties in binary mixtures of a biosurfactant derived from Camellia oleifera Abel and synthetic surfactants. J Colloid Interface Sci 2011; 359: 487-492.

34. Noriega SE and Subramanian A. Consequences of neutralization on the proliferation and cytoskeletal organization of chondrocytes on chitosan-based matrices. Int $J$ Carbohydr Chem 2011; 2011: 809743.

35. Chaudhari A, Gite V, Rajput S, et al. Development of eco-friendly polyurethane coatings based on neem oil polyetheramide. Ind Crop Prod 2013; 50: 550-556.

36. Jerobin J, Sureshkumar RS, Anjali $\mathrm{CH}$, et al. Biodegradable polymer based encapsulation of neem oil nanoemulsion for controlled release of Aza-A. Carbohydr Polym 2012; 90: 1750-1756.

37. Shikata $\mathrm{T}$ and Okuzono M. Are all polar molecules hydrophilic? Hydration numbers of ketones and esters in aqueous solution. $J$ Phys Chem $B$ 2013; 117: 7718-7723.

38. Ameh AO, Muhammad JA and Audu HG. Synthesis and characterization of antiseptic soap from neem oil and shea butter oil. African Journal of Biotechnology 2013; 12: 4656-4662. 